\title{
Prevalence of frailty syndrome in old people in a hospital institution
}

\author{
Daniela Ramos Oliveira ${ }^{1}$ \\ Luiz Antonio Bettinelli² \\ Adriano Pasqualotti ${ }^{2}$ \\ Débora Corso ${ }^{3}$ \\ Felipe Brock ${ }^{4}$ \\ Alacoque Lorenzini Erdmann ${ }^{5}$
}

Objective: to measure the prevalence of frailty syndrome in elderly inpatients in a hospital institution. Methods: cross-sectional study using a sample of 99 subjects aged 65 or older, hospitalized in the month of November/2010 in São Vicente de Paulo Hospital in Passo Fundo, Rio Grande do Sul state (RS). Data were collected regarding the phenotype of the frailty, along with social and demographic, clinical and anthropometric information. Results: the mean age was $74.5 \pm 6.8$ years and $50(50.5 \%)$ were women. $4 \%$ were classified as non-frail, $49(49.5 \%)$ as pre-frail and $46(46.5 \%)$ as frail. No statistically significant factors were identified that were associated with frailty. Conclusions: as was expected, the prevalence in this population was found to be high compared to other studies that focused on the community. It is believed that early detection and interdisciplinary intervention can prevent the progression of the condition and reduce the incidence of complications and hospitalization.

Descriptors: Health of the Elderly; Hospitalization; Prevalence.

\footnotetext{
1 MSc, RN, Hospital de Câncer de Barretos, Barretos, SP, Brazil

2 PhD, Full Professor, Universidade de Passo Fundo, Passo Fundo, RS, Brazil.

${ }^{3}$ RN, Hospital São Vicente de Paulo, Passo Fundo, RS, Brazil.

${ }^{4}$ Master's student, Universidade de Passo Fundo, Passo Fundo, RS, Brazil. RN, Hospital São Vicente de Paulo, Passo Fundo, RS, Brazil.

${ }^{5}$ PhD, Full Professor, Centro de Ciências da Saúde, Universidade Federal de Santa Catarina, Florianópolis, SC, Brazil.
}

\author{
Corresponding Author: \\ Luiz Antonio Bettinelli \\ Universidade de Passo Fundo \\ Rua Marcelino Ramos, 111 \\ Centro \\ CEP: 99010-160, Passo Fundo, RS, Brasil \\ E-mail: bettinelli@upf.br
}




\section{Introduction}

Brazil is currently undergoing an accelerated aging process, with profound changes to the age distribution of the population ${ }^{(1)}$. As societies age, health problems among the elderly challenge health and social security systems. Currently we are witnessing a "geriatrization" of the Brazilian hospital setting ${ }^{(2-3)}$. Such a scenario demands the identification of the elderly people who are at the greatest risk of becoming sick, in order to improve the adoption of measures for organizing interventions and preventive care, ensuring that decision-making in relation to choice of priorities is done equitably and efficiently ${ }^{(3)}$.

Frailty is a multidimensional syndrome, involving complex interactions between biological, psychological and social factors in the course of an individual's life, that culminates in a state of increased vulnerability associated with an increased risk of adverse outcomes such as clinical delirium, functional decline, impaired mobility, falls, social withdrawal, increased morbidity and mortality and hospitalization ${ }^{(4-5)}$.

There is still not yet a scientific consensus regarding the term frailty, its definition and its indicators, nor how it might be identified or evaluated(6-7), however, the most widely accepted concept today is that frailty should be characterized as a clinical syndrome, identified by unintentional weight loss, lowering of physical activity, reduced muscle strength - evidenced by reduced grip strength, feeling of fatigue and reduced walking speed. Those with three of these symptoms would be characterized as frail, those with one or two symptoms defined as pre-frail and those without any of these symptoms classified as non-frail or robust ${ }^{(6)}$. This phenotype(6) is easy to apply and low cost. It makes possible early identification and adoption of specific preventive measures that can eliminate or delay the signs and symptoms of the syndrome. There is a consensus in the scientific community that more studies are needed to define frailty syndrome better, which sets of symptoms and signs characterize it, and what signs, singly or together, are the markers for frailty syndrome or specific frailties(8-9). Accordingly, while awaiting a more conclusive operating definition, in this study we have chosen the model developed at Johns Hopkins University(6).

It is estimated that from $10-25 \%$ of people over 65 and $46 \%$ over age 85 , who live in the community, are frail ${ }^{(4)}$. The prevalence of frailty in the Cardiovascular Health Study, carried out in the United States with 5,317 participants aged 65 and over was $6.9 \%{ }^{(6)}$. Another study ${ }^{(10)}$ showed that $7 \%$ of the U.S. population over 65 and 30\% of those 80 and over were frail. There is little data on the prevalence of frailty syndrome in the elderly, particularly due to the lack of a consensus on a definition that can be used for screening in different populations $^{(11)}$.

Knowing how to diagnose frailty and getting to know the profile of the hospitalized elderly is of great importance because it allows insight into the question of interdisciplinary care during hospitalization. The prevalence of frailty in this population is unknown, locally, nationally and internationally. Therefore, it is essential to understand the problem of geriatric syndromes in the hospital environment and their implications for care.

Within this perspective the question is: what is the prevalence of frailty syndrome in older people in hospital institutions? To answer this question, our objective has been to measure the prevalence of frailty syndrome in the elderly in a hospital institution in terms of sociodemographic, clinical and anthropometric variables.

\section{Methodology}

A cross-sectional study measured the prevalence of frailty syndrome in elderly hospitalized patients aged 65 years or more in the São Vicente de Paulo Hospital (HSVP) during November 2010, totaling 99 elderly people. We chose to include in this study elderly people of 65 years of age or more because the criteria established for defining frailty syndrome(6) have been validated for elderly people from this age group. In a review study ${ }^{(12)}$, all publications had a population range age of equal to or older than 65. HSVP hospital is a tertiary teaching hospital, with macro-regional scope com, integrated into the SUS public health system and has 617 inpatient beds. The total number of admissions during the month of November 2010 the institution was 2590 . The number of elderly people aged 65 years or more in the same period was 697 and the average stay was five days. Among the leading causes of hospitalization include cardiovascular, pulmonary, strokes and renal problems.

The elderly people agreed to participate in the study, by signing the Instrument of Informed Consent (IC). Elderly people who were discharged or died within the first 72 hours were excluded from this study as were those interned in closed units (emergency room, recovery room, ICU, the surgical center and hemodynamic studies unit); those confined to bed; those in wheelchairs, unable to walk; those with limiting 
neurological disease; those with extensive skin lesions; those with amputations of the lower limbs; terminally ill patients and those with cognitive deficit suggesting dementia, as assessed using the Mini-Mental State Examination, and who were not accompanied by family members or caregivers. The study was approved by the Ethics Committee of the University of Passo Fundo (UPF) by opinion no. 197/2010 and by the Group for Research and Postgraduate studies at HSVP.

By means of a structured questionnaire, demographic, clinical, anthropometric data and criteria for frailty syndrome were collected, using the phenotype developed at Johns Hopkins University ${ }^{(6)}$. Exhaustion was assessed using the depression scale from the Center for Epidemiological Studies (CES-D). Grip strength was measured using a SAEHAN brand digital dynamometer. The verification procedure followed the recommendations of the American Society of Hand Therapists (ASHT) ${ }^{(13)}$. The level of physical activity was assessed using the Minnesota Leisure Time Physical Activity Questionnaire. The decrease in walking speed was assessed using the time taken to travel a distance of $4.6 \mathrm{~m}$.

To structure the database the application Microsoft Excel 2007 was used, and the statistical program Statistical Package for the Social Sciences (SPSS) version 17.0 for Windows was used for the analyses. Numerical variables were described as mean \pm standard deviation and the categories as absolute and relative frequencies. The associations between frailty and category variables were tested using Pearson's chisquare test and those between frailty and quantitative variables using variance analysis with a classification criterion. For multiple comparisons, Tukey's Post-hoc test. was used. Associations were considered significant when $\mathrm{p} \leq 0.05$.

\section{Results}

99 elderly people of mean age $74.5 \pm 6.8$ years took part in the study, of which 50 (50.5\%) were women. The average income of participants was $2.8 \pm 5.3$ minimum salaries, with the majority, 90 (90.9\%) retired and only two $(2 \%)$ reported that they were in paid work. The average number of years of formal education in this population was $5.2 \pm 4.5$ years and 17 (17\%) were illiterate. The majority of the elderly people, $53(53.5 \%)$ were married and lived in their own home, 84 (84.8\%). Regarding the number of children, the average was 3.2 \pm 0.7 . Table 1 shows the socio-demographic variables related to the diagnosis of frailty.

Table 1 - Description of the socio-demographic characteristics related to the diagnosis of frailty. Passo Fundo, RS, Brazil, 2011

\begin{tabular}{|c|c|c|c|c|c|}
\hline \multirow{2}{*}{ Characteristic } & \multicolumn{3}{|c|}{ Frailty diagnosis } & \multirow{2}{*}{ Total $(n=99)$} & \multirow{2}{*}{$\mathbf{p}$} \\
\hline & Non-frail $(n=4)$ & Pre-frail $(n=49)$ & Frail $(n=46)$ & & \\
\hline Sex & & & & & 0.995 \\
\hline Male & $2(4.1 \%)$ & $24(49.0 \%)$ & $23(46.9 \%)$ & 49 & \\
\hline Female & $2(4.0 \%)$ & $25(50.0 \%)$ & $23(46.0 \%)$ & 50 & \\
\hline Ethnicity & & & & & 0.177 \\
\hline White & $3(3.3 \%)$ & $45(49.5 \%)$ & $43(47.3 \%)$ & 91 & \\
\hline Black & $0(0 \%)$ & $0(0 \%)$ & $2(100 \%)$ & 2 & \\
\hline Colored & $1(16.7 \%)$ & $4(66.7 \%)$ & $1(16.7 \%)$ & 6 & \\
\hline Marital status & & & & & 0.216 \\
\hline Single & $0(0 \%)$ & $1(16.7 \%)$ & $5(83.3 \%)$ & 6 & \\
\hline Married & $2(3.8 \%)$ & $25(47.2 \%)$ & $26(49.1 \%)$ & 53 & \\
\hline Divorced & $1(20 \%)$ & $3(60 \%)$ & $1(20 \%)$ & 5 & \\
\hline Widowed & $1(2.9 \%)$ & $20(57.1 \%)$ & $14(40 \%)$ & 35 & \\
\hline Literacy & & & & & 0.644 \\
\hline Literate & $4(4.9 \%)$ & $40(48.8 \%)$ & $38(46.3 \%)$ & 82 & \\
\hline Illiterate & $0(0 \%)$ & $9(52.9 \%)$ & $8(47.1 \%)$ & 17 & \\
\hline Occupation & & & & & 0.367 \\
\hline Retired & $4(4.4 \%)$ & $41(45.6 \%)$ & $45(50 \%)^{*}$ & 90 & \\
\hline Pensioner & $0(0 \%)$ & $5(100 \%)$ & $0(0 \%)^{*}$ & 5 & \\
\hline Employed & $0(0 \%)$ & $1(100 \%)$ & $0(0 \%)^{*}$ & 1 & \\
\hline Freelance & $0(0 \%)$ & $1(100 \%)$ & $0(0 \%)^{*}$ & 1 & \\
\hline
\end{tabular}

Values express mean \pm standard deviation or absolute and relative frequency; * only $45(97.8 \%)$ elderly people replied 
The prevalence of frailty in this study was 4 (4\%) non-frail, 49 (49.5\%) pre-frail and 46 (46.5\%) frail elderly people. The mean age was higher in the group of frail elderly people when compared to the other groups, but this difference was not statistically significant $(p=0.843)$. Between the sexes, the prevalence of frailty was very similar $(p=0.995)$. Regarding ethnicity, whites accounted for the majority of the sample (92\%). As regards the prevalence of frailty related to marital status, it was observed that, despite the small number of single elderly people in the sample, $83.3 \%$ of these were frail $(p=0.216)$. The prevalence of non-frail, pre- frail and frail elderly people with relation to literacy was similar between the groups $(p=0.644)$. There was no statistically significant difference when the number of years of schooling were compared with the prevalence of frailty, however, non-frail elderly people had more years of schooling then the pre-frail and frail groups $(p=0.397)$. Unlike what had been expected, the average income was higher in the group of frail elderly people when compared to the other groups, but this difference was not statistically significant $(p=0.958)$. Table 2 shows the prevalence of frailty related to comorbidity.

Table 2 - Association of comorbidity with frailty syndrome. Passo Fundo, RS, Brazil, 2011

\begin{tabular}{|c|c|c|c|c|c|}
\hline \multirow{2}{*}{ Comorbidity } & \multicolumn{3}{|c|}{ Frailty diagnosis } & \multirow{2}{*}{ Total $(n=99)$} & \multirow{2}{*}{$\mathbf{p}$} \\
\hline & Non-frail $(n=4)$ & Pre-frail (n=49) & Frail $(n=46)$ & & \\
\hline Diabetes mellitus & & & & & 0.202 \\
\hline Yes & $0(0 \%)$ & $9(39.1 \%)$ & $14(60.9 \%)$ & 23 & \\
\hline No & $4(5.3 \%)$ & $40(52.6 \%)$ & $32(42.1 \%)$ & 76 & \\
\hline Systemic arterial hypertension & & & & & 0.915 \\
\hline Yes & $3(4.5 \%)$ & $32(48.5 \%)$ & $31(47 \%)$ & 66 & \\
\hline No & $1(3 \%)$ & $17(51.5 \%)$ & $15(45.5 \%)$ & 33 & \\
\hline Cardiovascular & & & & & 0.678 \\
\hline Yes & $1(2.4 \%)$ & $20(28.8 \%)^{*}$ & $20(48.8 \%)^{\dagger}$ & 41 & \\
\hline No & $3(5.6 \%)$ & $28(51.9 \%)^{*}$ & $23(42.6 \%)^{\dagger}$ & 54 & \\
\hline Rheumatism & & & & & 0.993 \\
\hline Yes & $1(4.2 \%)$ & $12(50 \%)^{\ddagger}$ & $11(45.8 \%)^{\S}$ & 24 & \\
\hline No & $3(4.2 \%)$ & $35(48.6 \%)^{\ddagger}$ & $34(47.2 \%)^{\S}$ & 72 & \\
\hline Osteoporosis & & & & & 0.971 \\
\hline Yes & $1(5 \%)$ & $10(50 \%)^{*}$ & $9(45 \%)^{\S}$ & 20 & \\
\hline No & $3(3.9 \%)$ & $38(49.4 \%)^{*}$ & $36(46.8 \%)^{\S}$ & 77 & \\
\hline \multicolumn{6}{|l|}{ Lungs } \\
\hline Yes & $0(0 \%)^{\|}$ & $7(41.2 \%)^{* *}$ & $10(58.8 \%)^{\dagger}$ & 17 & \multirow{2}{*}{0.475} \\
\hline No & $3(41 \%)^{\|}$ & $37(50.7 \%)^{\star *}$ & $33(45.2 \%)^{\dagger}$ & 73 & \\
\hline Cancer & & & & & 0.351 \\
\hline Yes & $0(0 \%)$ & $12(60 \%)^{\dagger \dagger}$ & $8(40 \%)^{\ddagger \ddagger}$ & 20 & \\
\hline No & $4(5.5 \%)$ & $33(45.2 \%)^{\dagger \dagger}$ & $36(49.3 \%)^{\ddagger \ddagger}$ & 73 & \\
\hline If Urinary Incontinence & & & & & 0.772 \\
\hline Yes & $0(0 \%)$ & $5(50 \%)^{\star *}$ & $5(50 \%)^{\dagger}$ & 10 & \\
\hline No & $4(4.9 \%)$ & $39(48.1 \%)^{* *}$ & $38(46.9 \%)^{\dagger}$ & 81 & \\
\hline Fecal incontinence & & & & & 0.764 \\
\hline Yes & $0(0 \%)$ & $3(42.9 \%)^{* *}$ & $4(57.1 \%)^{\dagger}$ & 7 & \\
\hline No & $4(4.8 \%)$ & $41(48.8 \%)^{\star *}$ & $39(46.4 \%)^{\dagger}$ & 84 & \\
\hline Depression & & & & & 0.547 \\
\hline Yes & $0(0 \%)$ & $8(61.5 \%)^{*}$ & $5(38.5 \%)^{\ddagger \ddagger}$ & 13 & \\
\hline No & $4(4.8 \%)$ & $40(48.2 \%)^{*}$ & $39(47 \%)^{\ddagger \ddagger}$ & 83 & \\
\hline Smoking & & & & & 0.001 \\
\hline Yes & $2(33.3 \%)$ & $2(33.3 \%)^{*}$ & $2(33.3 \%)$ & 6 & \\
\hline No & $2(2.2 \%)$ & $46(50 \%)^{*}$ & $44(47.8 \%)$ & 92 & \\
\hline
\end{tabular}

Values express mean \pm standard deviation or absolute and relative frequency;

*only $48(97.9 \%)$ elderly people replied

tonly $43(93.5 \%)$ elderly people replied

‡only $47(95.9 \%)$ elderly people replied

§only $45(97.8 \%)$ elderly people replied

I only $3(75 \%)$ elderly people replied

Ionly $44(89.8 \%)$ elderly people replied

**only $45(91.8 \%)$ elderly people replied

†tonly $44(95.6 \%)$ elderly people replied 
With the exception of smoking, there was no statistically significant difference when assessing the prevalence of frailty and the presence or not of comorbidities. In spite of the small probability value associated with this comparison, it should be noted that in this case, there was a violation of the assumptions behind statistical test used, since the 4 cells of the contingency table produced the expected values $<5$. As for their BMI, the non-frail elderly people had an average of $26.3 \pm 5.3$, the pre-frail, $27.1 \pm 5.0$ and the frail $26.6 \pm 5.4(0.667)$.

The prevalence of each of the proposed phenotypes in the methodological reference frame of non-frail, prefrail and frail elderly people is shown in Table 3.

Table 3 - Proposed(6) and frailty syndrome diagnosis. Passo Fundo, RS, Brazil, 2011

\begin{tabular}{|c|c|c|c|c|c|}
\hline \multirow{2}{*}{ Phenotype } & \multicolumn{3}{|c|}{ Frailty diagnosis } & \multirow{2}{*}{ Total $(n=99)$} & \multirow{2}{*}{$p$} \\
\hline & Not frail $(n=4)$ & Pre-frail $(n=49)$ & Frail $(n=46)$ & & \\
\hline Weight loss & & & & & 0.000 \\
\hline Yes & $0(0 \%)$ & $12(26.7 \%)^{*}$ & $33(73.3 \%)^{\dagger}$ & 45 & \\
\hline No & $4(7.8 \%)$ & $35(68.8 \%)^{*}$ & $12(23.5 \%)^{\dagger}$ & 51 & \\
\hline Exhaustion & & & & & 0.000 \\
\hline Yes & $0(0 \%)$ & $20(34.5 \%)^{*}$ & $38(65.5)^{\dagger}$ & 58 & \\
\hline No & $4(10.5 \%)$ & $27(71.1 \%)^{*}$ & $7(18.4 \%)^{\dagger}$ & 38 & \\
\hline Grip strength & & & & & 0.000 \\
\hline Yes & $0(0 \%)$ & $35(44.3 \%)$ & $44(55.7 \%)$ & 79 & \\
\hline No & $4(20.0 \%)$ & $14(70.0 \%)$ & $2(10.0 \%)$ & 20 & \\
\hline Physical activity & & & & & 0.009 \\
\hline Yes & $0(0 \%)$ & $4(22.2 \%)^{*}$ & $14(77.8 \%)^{\ddagger}$ & 18 & \\
\hline No & $4(5.3 \%)$ & $43(56.6 \%)^{*}$ & $29(38.2 \%)^{\ddagger}$ & 76 & \\
\hline Walking speed & & & & & 0.000 \\
\hline Yes & $0(0 \%)^{\S}$ & $9(22.5 \%)^{\|}$ & $31(77.5 \%)^{\pi}$ & 40 & \\
\hline No & $3(8.3 \%)^{\S}$ & $26(72.2 \%)^{\|}$ & $7(19.4 \%)^{\pi}$ & 36 & \\
\hline
\end{tabular}

Values express mean \pm standard deviation or absolute and relative frequency

*only $47(95.9 \%)$ of the patients did the test

tonly $45(97.8 \%)$ of the patients did the test

fonly $43(93.5 \%)$ of the patients did the test

§only $3(75 \%)$ of the patients did the test

I only $35(71.4 \%)$ of the patients did the test

Ionly $38(82,6 \%)$ of the patients did the test

When evaluating items and the proposed phenotype ${ }^{(6)}$, items it can be observed that those most frequently present in elderly people considered frail was decreased grip strength, followed by exhaustion, decreased walking speed, weight loss, and finally the least frequent item, the decrease in physical activity. All the phenotypes evaluated in this study, regardless of the frailty characterization of the groups of elderly people surveyed, showed statistically significant differences $(p \leq 0.05)$.

\section{Discussion}

The average age of the elderly people (74.5 \pm 6.8 years) was identical in another study ${ }^{(14)}$ (74.5 years).

In terms of prevalence, $49.5 \%$ of the elderly people proved to be pre-frail and $46.5 \%$ frail. A study ${ }^{(15)}$ showed a relationship with these findings, finding the following prevalence of frailty syndrome in elderly people in a hospital institution: $26.2 \%$ of those hospitalized in a clinical unit and $62.4 \%$ in a surgical unit. An extensive and systematic search is required to ensure that there are not actually any other studies with data on data frailty syndrome in hospital institutions. However, a search of the current database did not find any such data. In this study, there was a higher prevalence of frailty compared with studies focusing on the community. In the Cardiovascular Health Study(6), the prevalence was $6.9 \%$. Another study(16) found that $10 \%$ of the elderly people were frail, $46 \%$ with intermediate frailty, similar to the present case, and $44 \%$ non-frail. Another study ${ }^{(17)}$, evaluating the prevalence in Brazilian elderly people aged 65 or over, living in groups of convenience, showed $33 \%$ non-frail elderly people, $66 \%$ of pre-frail and only $1 \%$ frail elderly people. One possible explanation for this difference in prevalence may be due to the fact that our sample was composed of elderly people in hospital. A review ${ }^{(12)}$ identified that the 18 studies analyzed 
showed a wide variation in the prevalence of frailty, ranging generally from $6.9 \%$ to $21.0 \%$ for the frail state and $33 \%$ to $55 \%$ in a pre-frail condition.

There is a correlation between frailty and sex, with the prevalence higher in women than in $\operatorname{men}^{(6,12,15)}$, in contrast to the data in this study, no statistically significant association was found between the sex and the prevalence of frailty. Possibly this is related to the reason for hospitalization, with the men having more severe and disabling conditions.

In studies ${ }^{(6,16)}$ there was a statistically significant difference in the prevalence of frailty according to ethnicity, with a greater proportion in blacks than in whites. In the present study, the small number of black people precluded such an analysis.

This study identified a greater prevalence of frailty in elderly people with higher average incomes (insignificant difference). No explanation was found for this finding, but it is assumed that those with higher incomes have a better perception of self-care, quality of life and access to preventive medicine. As expected, according to one study(16), those with incomes below \$ 10,000 (US) per year are twice as likely to suffer from frailty as the richest.

Retirement proved to be an important triggering factor for frailty in elderly people, since $45.6 \%$ had intermediate frailty and 50\% were frail.

One study showed that there is no statistically significant trend of increasing prevalence of frailty in people with more diseases(6). Individuals with cardiovascular disease, renal failure, strokes, osteoarthritis and depression are significantly more likely to be classified as frail than people without these conditions, even after adjusting for age and sex ${ }^{(9)}$. Conversely, one study(6) showed a significant difference regarding the occurrence of hypertension and frailty, whereas the present study found no significant association between these variables. Certain conditions may share some of the same features of frailty, leading to a potential classification error. When people with depression or diabetes have symptoms that meet criteria for frailty, it is difficult to know if they really are frail(9).

Regarding diagnosis of frailty, decreased grip strength was observed in $80 \%$ of frail elderly people, exhaustion in 59\%, weight loss in $45 \%$, a decrease in walking speed of $40 \%$ and finally, decreased physical activity, found in only $18 \%$ of frail elderly people. Decreased grip strength was also the most frequent phenotype involved in the characterization of prefrail elderly people. Other authors ${ }^{(17)}$ also commonly identified decreased grip strength as the phenotype most often involved in the diagnosis of frailty syndrome and decreased physical activity as the phenotype the least involved. This piece of data is also corroborated by a study(18) that found the existence of a hierarchy in the manifestation of the factors associated with physical frailty and the risk of developing muscle weakness, slow gait and low physical activity level is 3.7, 1.7 and 1.9 times greater than the risk of developing weight loss, respectively. In addition, this same study found that whereas muscle weakness manifests itself at the start and is reversible, exhaustion and weight loss are markers evidencing the end of the frailty cycle and indicate elderly people who are prone to rapid progression in this cycle. In this context, it is concluded that it is not the number of markers that determines the risk of becoming frail but which markers appear first.

The frailty index is strongly correlated with risk of death, with a correlation coefficient greater than $0.95^{(5)}$. While in there, so far, a specific treatment for this syndrome, periodic comprehensive geriatric assessments by a multidisciplinary team may be able to slow the functional decline and prevent frailty and thus decrease the rate of institutionalization and hospitalization, positively changing rates of morbidity and mortality in this portion of the population. However, systematized protocols need to be established for the optimization of the rehabilitation of these patients ${ }^{(11)}$.

Assessing individual health needs of people who are frail requires an evaluation of their cognition, function, mobility, balance and social circumstances, in addition to understanding their medical problems, because frailty has important implications for the care needs of elderly people affected by the syndrome ${ }^{(5)}$.

Triage carried out in a hospital environment, prior to hospitalization might well be the most suitable time for a multidimensional assessment of the elderly person, in order to classify him or her according to the level of frailty. This would allow the professional to direct the care, enabling the nursing assistants to focus on potential needs of the elderly person. It is believed that a barrier to characterizing such patients is the absence of standardized instruments and for assessing frailty syndrome in elderly people.

The availability of a reliable and validated instrument to assess frailty among elderly people in Brazil is very useful for health professionals, both for research and in clinical practice(7).

Data on the comparison of the phenotype of frailty with the physiological changes of aging, as 
well as the sickness conditions and the impact of hospitalization on the phenotype variables were not analyzed because the cross-sectional design of the study does not allow one to infer causality. However, it is known that both the factors that led the patient to be hospitalized and the hospital itself may adversely affect health conditions, even though temporarily, changing the classification of the patient with regard to the phenotype as determined(6). Even with this limitation, the identification of the situation of the elderly with regard to frailty at the time of admission to hospital is of great importance, as it modifies planning for care by the nursing staff and other therapeutic work carried out by the multidisciplinary team.

\section{Conclusions}

Assessing and identifying frailty syndrome in elderly people is a current problem for health professionals working on the implementation of specific programs in order to minimize the effects and consequences of frailty. The nursing staff may be present at all levels of care to these patients, optimizing their quality of life

No factors were identified that were statistically associated with frailty. As was expected, the prevalence in this population was high compared with studies that focus on non-hospitalized elderly people.

The present study has limitations, because crosssectional studies do not allow one to distinguish between cause and effect. One might question whether the use of a static frailty model, measured at a single point in time, would be appropriate for assessing a dynamic condition involving changes over the time in hospital and later, after being discharged. Longitudinal studies with larger populations would perhaps answer such questions better.

It is believed that the first 72 hours represent a period when the person hospitalized can show hemodynamic changes. Accordingly, the question arises whether the diagnosis of frailty should be at the time when the elderly person is more stable from a clinical point of view. Elderly people in the acute stage of a disease, especially in the first few days after at mission to hospital, may exhibit signs and symptoms that mask or overestimate frailty.

The aim of this study has been achieved by demonstrating the prevalence of frailty syndrome in elderly people in a hospital institution. It is hoped that, with these results, models of diagnosis and care for the frail elderly (early detection and treatment) and for the non-frail elderly (primary prevention) will be suggested, benefiting health professionals, the elderly and society. In this manner, progression of the condition may be avoided, reducing the incidence of complications, length of hospital stay and readmissions of elderly clients. It is thought that a multi disciplinary intervention, supported by public health initiatives is an efficient and effective strategy for care to frail old people.

\section{References}

1. Instituto Brasileiro de Geografia e Estatística (IBGE). Indicadores Sociodemográficos e de Saúde no Brasil [Internet]. Rio de Janeiro: Ministério do Planejamento, Orçamento e Gestão; 2009. [acesso 3 mar 2010]. Disponível em: http://www.ibge.gov.br/ home/estatistica/populacao/indic_sociosaude/2009/ indicsaude.pdf.

2. Veras RP, Caldas CP. Produção de cuidados à pessoa idosa. Ciência Saúde Coletiva. 2008;13(4):1104.

3. Estrella K, Oliveira CEF, Sant'anna AA, Caldas CP. Detecção do risco para internação hospitalar em população idosa: um estudo a partir da porta de entrada no sistema de saúde suplementar. Cad Saúde Pública. 2009;25(3):507-12.

4. Ministério da Saúde (BR). Secretaria de Atenção à Saúde. Departamento de Atenção Básica. Envelhecimento e saúde da pessoa idosa. Brasília, DF: Ministério da Saúde; 2006.

5. Koller K, Rockwood K. Frailty in older adults: Implications for end-of-life care. Cleveland Clin J Medicine. 2013;80(3):168.

6. Fried LP, Tangen CM, Walston J, Newman AB, Hirsch, C, Gottdiener J, et al.Frailty in older adults: evidence for a phenotype. J Gerontol Series A - Biological Sciences and Medical Sciences. 2001;56(3):146-56.

7. Fabrício-Wehbe SCC, Schiaveto FV, Vendrusculo TRP, Haas VJ, Dantas RAS, Rodrigues RAP. Cross-cultural adaptation and validity of the "Edmonton Frail Scale - EFS" in a Brazilian elderly sample. Rev. Latino-Am. Enfermagem. 2009;17(6):1043-9.

8. Fried LP, Hadley EC, Walston JD, Newman AB, Guralnik JM, Studenski S, et al. From bedside to bench: research agenda for frailty. Sci Aging Knowledge Environ. 2005;(31):25.

9. Bergman $H$, Ferrucci $L$, Guralnik JM, Hogan DB, Hummel S, Karunananthan S, et al. Frailty: an emerging research and clinical paradigm - issues and controversies. J Gerontol Series A - Biological Sciences and Medical Sciences. 2007;62(7):731-7. 
10. Singh M, Alexander K, Roger VL, Rihal CS, Whitson $\mathrm{HE}$, Lerman $A$, et al. Frailty and its potential relevance to cardiovascular care. Fragilização e sua potencial relevância para cuidados cardiovasculares. Mayo Clinic Proc. 2008;83(10):1146-53.

11. Macedo C, Gazzola JM, Najas M. Síndrome da fragilidade no idoso: importância da fisioterapia. Arq Brase Ciências Saúde. 2008;33(3):177-84.

12. Tribess $\mathrm{S}$, Oliveira RJ. Síndrome da fragilidade biológica em idosos: revisão sistemática. Rev Salud Pública. 2011;13(5):853-64.

13. Figueiredo IM, Sampaio RF, Mancini MC, Silva FCM, Souza MAP. Teste de força de preensão utilizando o dinamômetro Jamar. Acta Fisiátrica. 2007;14(2):104-10. 14. Santos ASR, Souza PA, Valle AMD, Cavalcanti ACD, Sá SPC, Santana RF. Caracterização dos diagnósticos de enfermagem identificados em prontuários de idosos : um estudo retrospectivo. Texto Contexto Enferm. 2008;17(1):141-9.

15. Crossetti MGO, Antunes M. Nursing disgnoses of those with frail eldrely syndrome in surgical impatient units. Anais da NANDA International 40th Anniversary Conference; 2012.

16. Szanton SL, Seplaki CL, Thorpe JR, Roland J, Fried LP. Socioeconomic Status is associated with Frailty: the Women's Health and Aging Studies. J Epidemiol Commun Health. 2010;64(1):63-7.

17. Carmo LV, Drummond LP, Arantes PMM. Avaliação do nível de fragilidade em idosos participantes de um grupo de convivência. Fisioter Pesqui.2011;18(1):17-22.

18. Xue QL, Roche KB,Varadhan R, Zhou J, Fried LP. Initial manifestations of frailty criteria and the development of frailty phenotype in the Women's Health and Aging Study II. J Gerontol: Medical Sciences. 2008;63(9):984-90. 